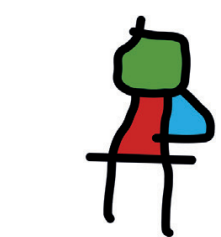

SEICAIP

\section{Allergologia et immunopathologia}

Sociedad Española de Inmunología Clínica, Alergología y Asma Pediátrica

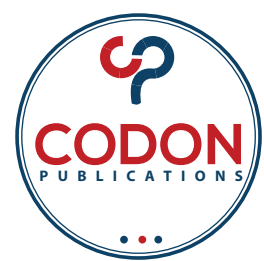

ORIGINAL ARTICLE

OPEN ACCESS CC(1)(2)

\title{
Low prevalence of asthma in Mexican children and adults with a positive rtRT-PCR test for SARS-CoV-2: a cross-sectional study during the 2020 pandemic
}

\author{
Martín Bedolla-Barajas ${ }^{a *}$, Jaime Morales-Romero ${ }^{b}$, Tonatiuh Ramses Bedolla-Pulidoc, \\ Carlos Meza-López ${ }^{c}$, Martín Robles-Figueroad, Norma Angélica Pulido-Guilléne, \\ Luis Gustavo Orozco-Alatorrec ${ }^{c}$, Carlos Alberto Andrade-Castellanos ${ }^{d}$
}

\author{
aServicio de Alergia e Inmunología Clínica, Nuevo Hospital Civil de Guadalajara “Dr. Juan I. Menchaca”, Guadalajara, México \\ bInstituto de Salud Pública, Universidad Veracruzana, Veracruz, México \\ "Servicio de Pediatría, Hospital Civil de Guadalajara "Dr. Juan I. Menchaca”, Guadalajara, México \\ 'Servicio de Medicina Interna, Nuevo Hospital Civil de Guadalajara "Dr. Juan I. Menchaca”, Guadalajara, México \\ ePsicología Clínica, Guadalajara, México
}

Received 18 January 2020; Accepted 22 November 2020

Available online 1 May 2021

\section{KEYWORDS}

asthma;

COVID-19;

cross-sectional study; children;

adults

\begin{abstract}
Background: It has recently been argued that asthma does not increase the risk of severe acute respiratory syndrome coronavirus-2 (SARS-CoV-2) infection. If so, the prevalence of asthma in subjects diagnosed with COVID-19 should be lower than in the general population.

Objective: To determine the prevalence of asthma in Mexican children and adults with SARSCoV-2 infection.

Methods: A public database of the Epidemiological Surveillance System for Viral Respiratory Disease in Mexico was analyzed. Those who underwent the real-time reverse transcriptase-polymerase chain reaction-SARS-CoV-2 (rtRT-PCR-SARS-CoV-2) test from February 27 to June 21, 2020, were included. In addition to the prevalence of asthma, some factors associated with it were investigated.

Results: Data from 417,366 subjects were analyzed. Asthma prevalence in children, adults, and global were $3.7 \%, 3.3 \%$, and $3.3 \%$, respectively. Although the asthma prevalence was lower in SARS-CoV-2 positive over negative patients, significant differences were only found in adults ( $2.8 \%$ vs. $3.7 \%$ respectively; odds ratio $(O R)=0.74 ; 95 \%$ confidence interval $(\mathrm{Cl}): 0.71-0.77)$; but not in children (3.5\% vs. $3.8 \%$, respectively; $\mathrm{OR}=0.91 ; 95 \% \mathrm{Cl}$ : $0.76-1.10)$. Multivariate analysis showed in younger than 18 years that girls and immunosuppression were factors associated with a decrease in the odds to develop asthma. In adults, asthma was positively associated with females, obesity, smoking, immunosuppression, chronic obstructive pulmonary disease, arterial hypertension, and cardiovascular disease.
\end{abstract}

*Corresponding author: Martín Bedolla Barajas. Servicio de Alergia e Inmunología Clínica, División de Medicina Interna, Nuevo Hospital Civil de Guadalajara “Dr. Juan I. Menchaca”. Salvador Quevedo y Zubieta No. 740, Colonia La Perla, Guadalajara, Jalisco 44340, México. E-mail address: drmbedbar@gmail.com 
Conclusion: The prevalence of asthma in child and adult were lower than those previously reported. Our study seems to support the hypothesis that asthma patients have a lower risk of SARS-CoV-2 infection. Further studies are required to demonstrate the consistency of our findings. (C) 2021 Codon Publications. Published by Codon Publications.

\section{Introduction}

About 350 million people suffer are asthmatic worldwide. ${ }^{1}$ Its prevalence in children and adults range from $9.4 \%$ to $12.6 \%^{2}$ and $4.3 \%^{3}$, respectively.

In early 2020, World Health Organization declared the new coronavirus strain, Severe Acute Respiratory Syndrome Coronavirus-2 (SARS-CoV-2), as a public health issue. The main transmission of COVID-19 virus (Coronavirus disease 2019 ) is through exposure to respiratory secretion drops and contact with infected people. However, they can also spread from contaminated objects, air in closed places, and possibly fecal-oral transmission. ${ }^{4}$ The chances of this virus affecting asthmatic patients are high as they are easily susceptible to viral respiratory infections. ${ }^{5}$ Nevertheless, it seems it is not like that. First clinical and epidemiological reports at the beginning of the pandemic, have suggested that allergic diseases and asthma, among them, are not risk factors for SARS-CoV-2 infection. ${ }^{6,7}$

Due to scarce evidence of asthma in pandemic. The need of epidemiological studies demonstrating higher consistency in populations different from those where COVID19 was first reported (Wuhan, China). This study aims to determine asthma prevalence in Mexican children and adult samples who underwent a real-time reverse transcriptase-polymerase chain reaction (rtRT-PCR) test to detect SARS-CoV-2 and compare them to national and worldwide asthma.

\section{Material and methods}

\section{Design and subjects}

A cross-sectional study was conducted based on open data from the Epidemiological Surveillance System of Respiratory Viral Disease in México, from February 27 to June 21, 2020. This system includes 475 monitor units of respiratory viral disease distributed all over the Mexican territory and can be used as sample representativeness, as they comprise patients from communitarian health centers and general hospitals of different socioeconomic status. The Epidemiological Surveillance System of Respiratory Viral Disease system follows a sentinel surveillance model, which collects samples from $10 \%$ of the acute respiratory ambulatory cases, severe cases, and 100\% viral deaths. Open data published by "Dirección General de Epidemiología" (https://www.gob.mx/salud/documentos/ datos-abiertos-152127), is available to the general population for use and reuse. But the only limitation is that the information collected lacks variables to identify subjects as they are not recorded.
Clinical data were obtained from an epidemiological survey that included the following variables: sex, age, state of residence, current self-report of smoking, and personal asthma history. Coexistent diseases included: obesity, systemic arterial hypertension ( $\mathrm{SAH})$, diabetes, chronic obstructive pulmonary disease (COPD), chronic renal disease, cardiovascular disease (cardiac insufficiency, cardiac arrhythmias, or coronary artery disease), and immunosuppression (usage of chemotherapy in patients with cancer, systemic steroids, or AIDS).

\section{SARS-CoV-2 detection}

In Mexico, SARS-CoV-2 presence is detected through rtRTPCR technique. Each lab performing tests is officially certified by the "Instituto de Diagnóstico y Referencia Epidemiológicos.”

\section{Ethics}

This study followed ethical principles for medical research in humans as per the Helsinki Declaration. This research is a retrospective analysis of open data provided by the Mexican Government for public access, usage, reuse, and redistribution. It is considered 'not risky,' according to Mexican legislation and article 17 of "Reglamento de la Ley General de Salud en Materia de Investigación para la Salud" as they do record the personal information of any individual. The participating researchers did not receive any special payment for this study and declared that they had no conflicts of interest.

Once unloaded, data were exported from Microsoft Excel (Redmond, WA) to IBM SPSS Statistics for Windows (Armonk, NY). Some inconsistencies and lost values were detected prior to the analysis; thus, reclassification of variables was performed for its introduction in multivariate models.

\section{Statistical analysis}

The descriptive and inferential statistic was performed. Asthma prevalence was assessed globally and in children and adults from Mexico and combined groups (at the national level and state by state). Confidence intervals of $95 \%$ for proportions, were calculated. Comparison of sex, age, smoking, diabetes background, COPD, immunosuppression, SAH, cardiovascular disease, obesity, and chronic renal disease between subjects with and without asthma, was assessed by chi-square test. Multivariate models utilizing logistic regression were created separately for the whole sample, children, and adults using IBM SPSS Statistics 
for Windows, Version 23, Armonk, NY. The independent variable was asthma presence, and covariates were sex, age, obesity, smoking, COPD, immunosuppression, SAH, and cardiovascular disease. A $p \leq 0.05$ was considered statistically significant.

\section{Results}

During the period of analysis, a total of 479,528 children or adults underwent rtRT-PCR test to identify SARS-CoV-2 infection, but finally, only 417,366 subjects were analyzed (Figure 1) due to the following reasons: no results in rtRTPCR (56,590); foreigners (2563); and incomplete data or mistakes in codification (3009).

Of the total population selected, women constituted $50.6 \%$ and men $49.4 \%$. Adult population resulted in $95.6 \%$, and pediatric was $4.4 \%$. Mean age in adults and children were $44.1 \pm 15.2$ and $8.4 \pm 5.8$ years, respectively.

Table 1 provides the prevalence of asthma at the national level in children, and adults who requested the performance of the rtPCR-SARS-CoV-2 test. The global prevalence of asthma was 3.3\%. The states of Mexico with the highest prevalence were: Sonora (6.2\%), Yucatan (5.7\%), and Quintana Roo (5.3\%); at the same time, the ones with the least prevalence were: Hidalgo (2.2\%), Puebla (1.9\%), and Tlaxcala (1.7\%).

As shown in Table 1 the asthma prevalence in children of Mexico is was $3.7 \%$. States of the country with the highest asthma frequency were: Sonora (9.4\%), Nayarit (8.4\%), and Chihuahua (7.8\%); and with the least frequency: Coahuila (2.3\%), Michoacan (2.0\%), and Tlaxcala (1.2\%).

Asthma in adults showed a prevalence of 3.3\% (Table 1). Once again, Sonora was the state with the highest asthma prevalence $(6.2 \%)$, followed by Yucatan (5.6\%), and Quintana Roo (5.3\%). On the other hand, Estado de Mexico (2.2\%), Tlaxcala (1.7\%), and Puebla $(1.9 \%)$ were the states with the least prevalence.

The prevalence of asthma in patients affected by COVID-19 was $2.8 \%$ in positives (4942 people with asthma $/ 178,306)$ and $3.7 \%$ in negative patients (8841 people with asthma $/ 239,060 ; p<0.0001)$. Similar prevalence was

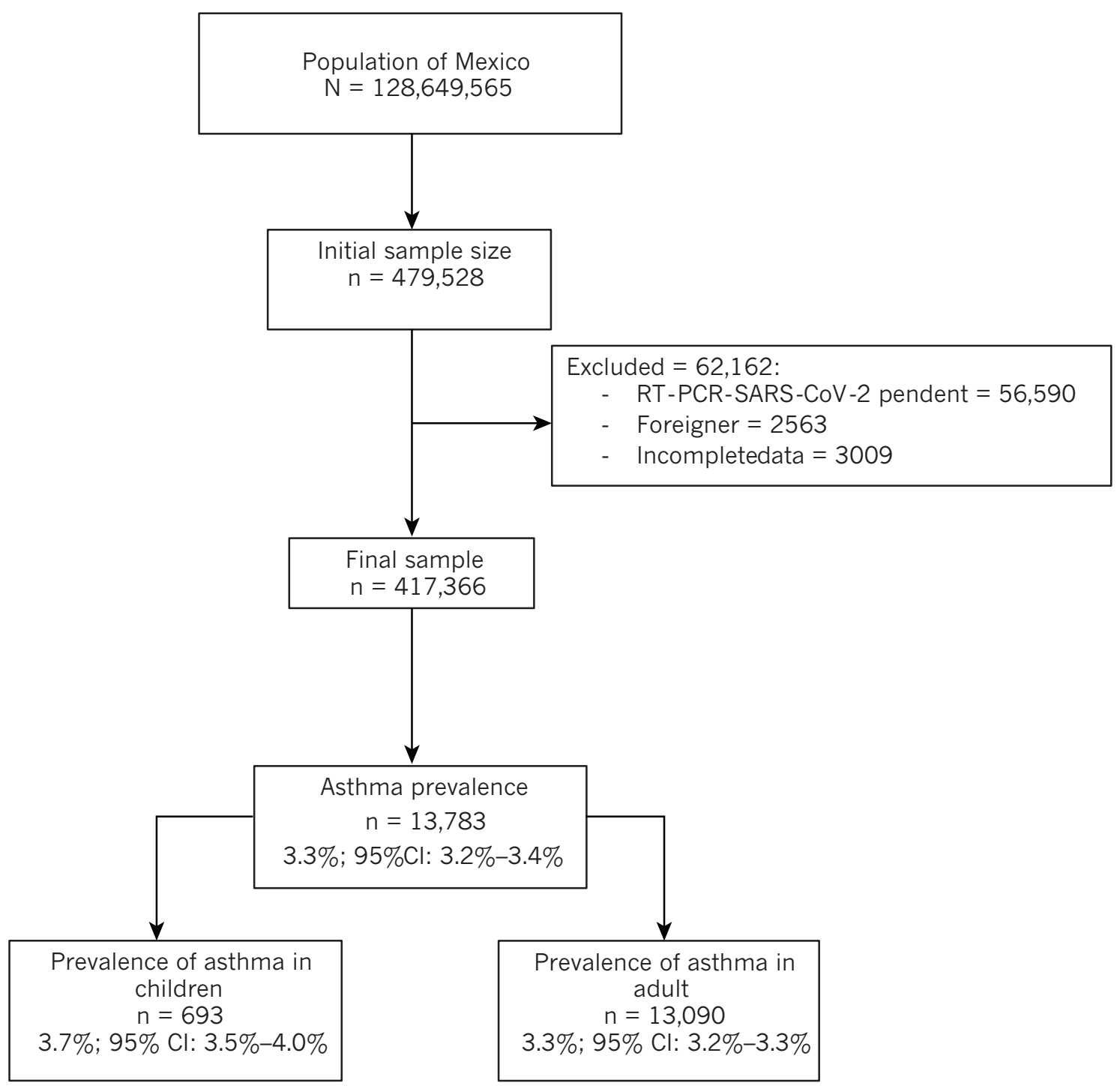

Figure 1 Selection of study subjects and prevalence of asthma in children and adults. 
Table 1 Prevalence of asthma in Mexico in subjects who were tested for rtRT-PCR-SARS-CoV-2.

\begin{tabular}{lrrcc}
\hline & \multicolumn{4}{c}{ Total } \\
\cline { 2 - 5 } & $\begin{array}{c}\text { Sample } \\
\text { size } \mathrm{n}\end{array}$ & $\begin{array}{c}\text { With } \\
\text { asthma }\end{array}$ & $\begin{array}{c}\text { Prevalence } \\
(\%)\end{array}$ & $\begin{array}{c}\text { 95\% Cl } \\
\text { (prevalence \%) }\end{array}$ \\
\hline All & 417,366 & 13,783 & 3.3 & 3.2 to 3.4 \\
Children & 18,487 & 693 & 3.7 & 3.5 to 4.0 \\
Adults & 398,879 & 13,090 & 3.3 & 3.2 to 3.3 \\
\hline
\end{tabular}

95\%Cl: 95\% confidence interval; rtRT-PCR-SARS-CoV-2: realtime reverse transcriptase-polymerase chain reaction to SARS-CoV-2. noted in adults too: $2.8 \%$ in positive adults $(4797 / 174,166)$ and $3.7 \%$ in negative adults (8293 /224,713; $p<0.0001)$. However, no significant differences were found in children: $3.5 \%$ in positive children (145/4140) and $3.8 \%$ in negative children (548 /14,347; $p=0.344)$. Table 2 provides the univariate analysis of factors associated with asthma in subjects who carried rtRT-PCR-SARS-CoV-2. Here, asthma prevalence was significantly more frequent in women (odds ratio $(O R)=1.71, p<0.0001$ ), in age groups from 6 to 11 years and 12 to 19 years $(O R=2.02, p<0.0001$ and $\mathrm{OR}=2.07, \quad p<0.0001$, respectively), current smokers $(\mathrm{OR}=1.08, p=0.012)$, COPD patients $(\mathrm{OR}=2.26, p<0.0001)$, immunosuppression $(\mathrm{OR}=1.69, p<0.0001), \mathrm{SAH}(\mathrm{OR}=1.22$, $p<0.0001)$, cardiovascular disease $(O R=1.60, p<0.0001)$, or obesity $(\mathrm{OR}=1.73, p<0.0001)$.

The multivariate analysis showed that asthma prevalence was 1.7 times more frequent in women than in men (Table 3 ). Adults showed $22 \%$ fewer odds to suffer asthma

Table 2 Univariate analysis of factors associated with asthma in subjects who underwent rtRT-PCR-SARS-CoV-2.

\begin{tabular}{|c|c|c|c|c|c|c|c|}
\hline & \multicolumn{2}{|c|}{ Total $n=417,366$} & \multicolumn{5}{|c|}{ With asthma $n=13,783$} \\
\hline & $n$ & $\%$ & $n$ & $\%$ & OR & $95 \% \mathrm{Cl}$ & $p^{*}$ \\
\hline \multicolumn{8}{|l|}{ Sex } \\
\hline Male & 211,151 & 50.6 & 5211 & 2.5 & 1 & & \\
\hline Female & 206,215 & 49.4 & 8572 & 4.2 & 1.71 & $1.65-1.77$ & $<0.0001$ \\
\hline \multicolumn{8}{|l|}{ Age, years } \\
\hline$\leq 5$ & 6918 & 1.7 & 154 & 2.2 & 1 & & \\
\hline $6-11$ & 4761 & 1.1 & 214 & 4.5 & 2.02 & $1.64-2.49$ & $<0.0001$ \\
\hline $12-19$ & 11,088 & 2.7 & 510 & 4.6 & 2.07 & $1.72-2.48$ & $<0.0001$ \\
\hline $20-39$ & 170,053 & 40.7 & 6258 & 3.7 & 1.65 & $1.41-1.94$ & $<0.0001$ \\
\hline $40-64$ & 181,521 & 43.5 & 5673 & 3.1 & 1.40 & $1.19-1.65$ & $<0.0001$ \\
\hline$\geq 65$ & 43,025 & 10.3 & 974 & 2.3 & 1.02 & $0.86-1.21$ & 0.848 \\
\hline \multicolumn{8}{|c|}{ Current smoker } \\
\hline No & 380,961 & 91.3 & 12,496 & 3.3 & 1 & & \\
\hline Yes & 36,405 & 8.7 & 1287 & 3.5 & 1.08 & $1.02-1.14$ & 0.012 \\
\hline Diabetes & 52,369 & 12.5 & & & & & \\
\hline No & 364,997 & 87.5 & 12,058 & 3.3 & 1 & & \\
\hline Yes & 52,369 & 12.5 & 1725 & 3.3 & 0.99 & 0.95-1.05 & 0.911 \\
\hline COPD & 6632 & 1.6 & & & & & \\
\hline No & 41,0734 & 98.4 & 13,297 & 3.2 & 1 & & \\
\hline Yes & 6632 & 1.6 & 486 & 7.3 & 2.26 & $2.06-2.49$ & $<0.0001$ \\
\hline \multicolumn{8}{|c|}{ Immunosuppression } \\
\hline No & 410,451 & 98.3 & 13,401 & 3.3 & 1 & & \\
\hline Yes & 6915 & 1.7 & 382 & 5.5 & 1.69 & $1.52-1.88$ & $<0.0001$ \\
\hline \multicolumn{8}{|c|}{ Systemic arterial hypertension } \\
\hline No & 349,124 & 83.6 & 11,130 & 3.2 & 1 & & \\
\hline Yes & 68,242 & 16.4 & 2653 & 3.9 & 1.22 & 1.17-1.27 & $<0.0001$ \\
\hline \multicolumn{8}{|c|}{ Cardiovascular disease } \\
\hline No & 407,638 & 97.7 & 13,277 & 3.3 & 1 & & \\
\hline Yes & 9728 & 2.3 & 506 & 5.2 & 1.60 & $1.46-1.75$ & $<0.0001$ \\
\hline \multicolumn{8}{|l|}{ Obesity } \\
\hline No & 348,706 & 83.5 & 10,282 & 2.9 & 1 & & \\
\hline Yes & 68,660 & 16.5 & 3501 & 5.1 & 1.73 & $1.66-1.80$ & $<0.0001$ \\
\hline \multicolumn{8}{|c|}{ Chronic kidney disease } \\
\hline No & 408,862 & 98.0 & 13,528 & 3.3 & 1 & & \\
\hline Yes & 8504 & 2.0 & 255 & 3.0 & 0.91 & $0.80-1.03$ & 0.115 \\
\hline
\end{tabular}

rtRT-PCR-SARS-CoV-2: real-time reverse transcriptase-polymerase chain reaction to SARS-CoV-2; COPD: chronic obstructive pulmonary disease; OR: odds ratio calculated in a tetrachoric table (the reference group is indicated as OR=1); $95 \% \mathrm{Cl}$ : $95 \%$ confidence interval. *Statistical analysis was performed using the chi-square test. 
Table 3 Multivariate analysis of factors associated with asthma in subjects who underwent rtRT-PCR-SARS-CoV-2.

\begin{tabular}{|c|c|c|c|c|c|c|c|c|c|}
\hline & \multicolumn{3}{|c|}{ Asthma } & \multicolumn{3}{|c|}{ Asthma in children } & \multicolumn{3}{|c|}{ Asthma in adults } \\
\hline & $\mathrm{aOR}$ & $95 \% \mathrm{Cl}$ & $p$ & $\mathrm{aOR}$ & $95 \% \mathrm{Cl}$ & $p$ & $\mathrm{aOR}$ & $95 \% \mathrm{Cl}$ & $p$ \\
\hline \multicolumn{10}{|l|}{ Sex } \\
\hline Male & 1 & & & 1 & & & 1 & & \\
\hline Female & 1.71 & $1.65-1.78$ & $<0.0001$ & 0.69 & $0.59-0.81$ & $<0.0010$ & 1.80 & $1.74-1.87$ & $<0.0001$ \\
\hline \multicolumn{10}{|l|}{ Age } \\
\hline Child, $<18$ years & 1 & & & - & - & - & - & - & - \\
\hline Adults, $\geq 18$ years & 0.78 & $0.71-0.83$ & $<0.0001$ & - & - & - & - & - & - \\
\hline \multicolumn{10}{|l|}{ Obesity } \\
\hline No & 1 & & & 1 & & & 1 & & \\
\hline Yes & 1.70 & $1.64-1.78$ & $<0.0001$ & 2.84 & $2.12-3.80$ & $<0.0010$ & 1.69 & $1.62-1.76$ & $<0.0001$ \\
\hline \multicolumn{10}{|l|}{ Current smoker } \\
\hline No & 1 & & & & & & 1 & & \\
\hline Yes & 1.09 & $1.03-1.16$ & 0.003 & - & - & 0.796 & 1.11 & $1.04-1.17$ & 0.001 \\
\hline \multicolumn{10}{|l|}{ COPD } \\
\hline No & 1 & & & - & - & - & 1 & & \\
\hline Yes & 2.04 & $1.85-2.25$ & $<0.0001$ & - & - & - & 2.03 & $1.84-2.24$ & $<0.0001$ \\
\hline \multicolumn{10}{|l|}{ Immunosuppression } \\
\hline No & 1 & & & 1 & & & 1 & & \\
\hline Yes & 1.51 & $1.36-1.68$ & $<0.0001$ & 0.49 & $0.28-0.83$ & 0.009 & 1.63 & $1.46-1.82$ & $<0.0001$ \\
\hline \multicolumn{10}{|l|}{$\begin{array}{c}\text { Systemic arterial } \\
\text { hypertension }\end{array}$} \\
\hline No & 1 & & & & & & 1 & & \\
\hline Yes & 1.05 & $1.00-1.10$ & 0.039 & - & - & 0.870 & 1.05 & $1.00-1.10$ & 0.040 \\
\hline \multicolumn{10}{|c|}{ Cardiovascular disease } \\
\hline No & 1 & & & & & & 1 & & \\
\hline Yes & 1.31 & $1.19-1.44$ & $<0.0001$ & - & - & 0.196 & 1.34 & $1.21-1.47$ & $<0.0001$ \\
\hline
\end{tabular}

aOR: adjusted odds ratio obtained by binary logistic regression. All variables were introduced in a dichotomous way by the Forward Conditional method. According to this method, those variables that meet the output criteria and are excluded from the model are not considered for the calculation of OR; rtRT-PCR-SARS-CoV-2: real-time reverse transcriptase-polymerase chain reaction to SARS-CoV-2; 95\% Cl: 95\% confidence interval; COPD: chronic obstructive pulmonary disease.

rtRT-PCR-SARS-CoV-2: real-time reverse transcriptase-polymerase chain reaction to SARS-CoV-2;

95\% Cl: $95 \%$ confidence interval;

COPD: chronic obstructive pulmonary disease.

than the pediatric population; obesity, smoking, COPD, $\mathrm{SAH}$, cardiovascular disease, and immunosuppression factors were significantly associated $(p<0.01)$ with asthma. Additionally, girl subjects younger than 18 years and immunosuppression factor decreased the odds to develop asthma but increased the chances to develop obesity. In the adult group, asthma was positively associated with females, obesity, smoking, immunosuppression, COPD, SAH, and cardiovascular disease.

\section{Discussion}

To the best of our knowledge, this is the first epidemiological study performed during the pandemic that describes asthma prevalence in the Mexican population taking the trRT-PCR-SARS-CoV-2 test. According to the study results, asthma prevalence in both children and adults was lesser than previously reported.

Interpretation of our findings related to low asthma prevalence in children and adults should considere asthma burden worldwide and locally. . Phase III of 'The International Study of Asthma and Allergies in Childhood,' assessed asthma prevalence in two age groups: 6 to 7 and 13 to 14 years, occurrence worldwide resulted in
9.4\% and 12.6\%; in Latin America 11.2\% and 13.6\%; and in Mexico $5.9 \%$ and $6.9 \%$, respectively. ${ }^{2}$ More recently, similar findings were also recorded in our country. In a local study, in almost 8 thousand children aged 3-15 years in Morelos: asthma prevalence was $11.9 \% .^{8}$ Two other studies in Jalisco with children aged 6 to 7 and 15 to 18 years demonstrated an $8 \%$ and $12.7 \%$ asthma prevalence, respectively. 9,10

Finally, 'Global Asthma Network Mexico' reported the most recent asthma prevalence in children aged 6-7 and 13-14 years: $5.8 \%$ and $7.5 \%$, respectively. ${ }^{11}$ This prevalence contradicted with the one observed in our study (3.7\%).

Besides, in the adult population, the study by To et al. $^{3}$ in 70 countries, including more than 178,000 adults aged 18 to 45 years, showed $4.3 \%$ global asthma prevalence with minimal variations as $0.2 \%$ in China to $21 \%$ in Australia; Latin America reported $4.3 \%$ and Mexico in particular, had $2.4 \%$.

A population-based study in Mexico City, including more than 1000 adults older than 40, showed an asthma prevalence of $5 \% .^{12}$ Even more, in Guadalajara, Mexico, asthma prevalence in women went from $4.2 \%$ to $8.5 \%$ and in men $3.5 \%$ to $5.7 \% .^{13,14}$

In summary, children and adult's prevalence in our study in most states of Mexico was lower than the disease 
burden reported in previous studies, thus, it seems that asthma is not a risk factor for SARS-CoV-2 infection.

Our study has provided three possible outcomes for the low asthma prevalence during the COVID-19 pandemic: (a) Asthma sub-diagnosis, (b) Asthma could protect against COVID-19 disease, and (c) drugs for asthma control could lessen the risk of infection or symptoms of COVID-19.

The study by Halpin et al. ${ }^{15}$ showed contradictory outcomes. It reported that asthma patients had a higher probability of severe COVID-19 (up to 40\% more) than non-asthmatic patients. Nevertheless, ranking asthma group according to the presence of an allergy, non-allergic asthma group was found to increase this association significantly $(O R=1.48 ; p=0.003)$. In contrast, allergic asthma did not show a significant statistical association with severe COVID-19 $(p=0.09) .{ }^{16}$ Even more, the association of asthma and respiratory allergy with the expression ACE2 receptor in airway cells was assessed by Jackson et al. ${ }^{17}$ Two relevant facts emerged from this trial: first, the ACE2 receptor expression was less in asthma subjects and allergic sensitization compared to those subjects with no asthma neither allergic sensitization; remarkably, asthma patients with more allergic sensitization expressed ACE2 receptor in a limited quantity compared to those patients with asthma and without allergic sensitization; second, when patients with allergic rhinitis or asthma encountered allergens, expression of ACE2 receptor decreased significantly within the following hours after challenge. Since asthmaassociated allergic sensitization represented about $80 \%$ and $90 \%$ of the cases. ${ }^{18,} 19$ In our study, it might be that subjects who underwent an rtRT-PCR-SARS-CoV-2 test could be mainly those with non-atopic asthma.

Interestingly, in our study, it was observed that asthma prevalence was less in adults with a positive test of SARSCoV-2. Previous studies in China revealed that people with any allergic disease were not more susceptible to develop COVID-19. The clinical findings by the Epidemiology Working Group ${ }^{6}$ and Zhang et al. ${ }^{20}$ reported that chronic respiratory disease, presented a lesser prevalence of SARSCoV-2 infection over other comorbidities like SAH, diabetes, and cardiovascular disease. Another study by Li et al. ${ }^{7}$ compared clinical characteristics of patients with severe and non-severe COVID-19, the frequency of asthma of $0.7 \%$ and $1.1 \%(p=0.681)$, respectively. This highly contrasted with asthma prevalence in the Chinese population (6.4\%). Authors have suggested that the Th2 immune response in this study population could counteract inflammation induced by SARS-CoV-2. This inference supports our analysis. Other published literature also suggests that few patients with asthma are infected by SARS-CoV-2, ${ }^{21}$ but, this infection is not a significant cause of asthma exacerbation leading to hospitalization ${ }^{22,23}$ or death.,24 However, considering that asthma is a heterogeneous disease, further studies investigating the association between asthma and COVID-19 severity should be performed. Practicing physicians should be alert of this association and continue to provide evidence-based care to these patients according to both international and national guidelines.

\section{Limitations and strengths of the study}

Firstly, a little more than $10 \%$ of rtRT-PCR-SARS-CoV-2 tests results were missing during the data analysis. Secondly, the open database had no diagnostic certainty of asthma, allergic sensitization, and the survey research may have human errors. Leading and response bias are known factors that could lead respondents to answer incorrectly. Thirdly, more confusing variables may exist in the database that may have been overlooked. Finally, our study sample is not representative of the entire Mexican population as it was limited to people tested by rtRT-PCR to detect the SARS-CoV-2 virus. The study's strength is its data collection, performed by skilled physicians. They followed up the positive cases through active (repeated telephone calls) and passive (records and reports from the hospital) surveillance.

\section{Conclusion}

In summary, observed asthma prevalence in children and adults in the present study is significantly lesser than previously suggested global and national studies that strengthens the hypothesis standing for less risk of SARS-CoV-2 infection in asthma patients. More research needs to be performed to support this hypothesis.

\section{Conflict of interest}

The authors declare no potential conflicts of interest.

\section{References}

1. GBD 2016 Disease and Injury Incidence and Prevalence Collaborators. Global, regional, and national incidence, prevalence, and years lived with disability for 328 diseases and injuries for 195 countries, 1990-2016: A systematic analysis for the Global Burden of Disease Study 2016. Lancet. 2017;390:121159. https://doi.org/10.1016/S0140-6736(17)32154-2

2. Lai CK, Beasley R, Crane J, Foliaki S, Shah J, Weiland S, et al. Global variation in the prevalence and severity of asthma symptoms: Phase three of the International Study of Asthma and Allergies in Childhood (ISAAC). Thorax. 2009;64:476-83. https://doi.org/10.1136/thx.2008.106609

3. To T, Stanojevic S, Moores G, Gershon AS, Bateman ED, Cruz AA, et al. Global asthma prevalence in adults: Findings from the cross-sectional world health survey. BMC Public Health. 2012;12:204. https://doi.org/10.1186/1471-2458-12-204

4. Al Huraimel K, Alhosani M, Kunhabdulla S, Stietiya MH. SARS-CoV-2 in the environment: Modes of transmission, early detection and potential role of pollutions. Sci Total Environ. 2020;744:140946. https://doi.org/10.1016/j.scitotenv. 2020.140946

5. Novak N, Cabanillas B. Viruses and asthma: The role of common respiratory viruses in asthma and its potential meaning for SARS-CoV-2. Immunology. 2020;161(2):83-93. https://doi. org/10.1111/imm.13240 
6. Epidemiology Working Group for NCIP Epidemic Response, Chinese Center for Disease Control and Prevention. [The epidemiological characteristics of an outbreak of 2019 novel coronavirus diseases (COVID-19) - China, 2020]. Zhonghua Liu Xing Bing Xue Za Zhi. 2020; 41(2):113-22. Chinese. https://doi. org/10.3760/cma.j.issn.0254-6450.2020.02.003.

7. Li X, Xu S, Yu M, et al. Risk factors for severity and mortality in adult COVID-19 inpatients in Wuhan. J Allergy Clin Immunol. 2020;146:110-18. https://doi.org/10.1016/j.jaci.2020.04.006

8. Mancilla-Hernández E, González-Solórzano EVM, MedinaÁvalos MÁ, Barnica- Alvarado RH. Prevalencia de asma y sus síntomas en población escolar de Cuernavaca, Morelos, México [Prevalence of asthma and its symptoms in schoolchildren from Cuernavaca, Morelos, Mexico]. Rev Alerg Mex. 2016;63:351-57. Spanish. https://doi.org/10.29262/ram. v63i4.189

9. Bedolla-Barajas M, Javier Ramírez-Cervantes F, MoralesRomero J, Jesús Pérez-Molina J, Meza-López C, DelgadoFigueroa N. A rural environment does not protect against asthma or other allergic diseases amongst Mexican children. Allergol Immunopathol. 2018;46:31-38. https://doi. org/10.1016/j.aller.2017.01.010

10. Morales-Romero J, Bedolla-Barajas M, López-Cota GA, Bedolla-Pulido TI, Bedolla-Pulido TR, Navarro-Lozano E, et al. Tendencia de la prevalencia de asma y sus síntomas en los adolescentes tardíos mexicanos en un periodo de siete años [Trends in the prevalence of asthma and its symptoms in Mexican late adolescents over a 7-year period]. Rev Alerg Mex. 2018;65:331-40. Spanish. https://doi.org/10.29262/ram. v65i4. 392

11. Del-Rio-Navarro BE, Navarrete-Rodríguez EM, Berber A, Reyes-Noriega N, García-Marcos Álvarez L; et al. The burden of asthma in an inner-city area: A historical review 10 years after Isaac. World Allergy Organ J. 2020;13:100092. https:// doi.org/10.1016/j.waojou.2019.100092

12. García-Sancho C, Fernández-Plata R, Martínez-Briseño D, Franco-Marina F, Pérez-Padilla JR. Prevalencia y riesgos asociados con pacientes adultos con asma de 40 años o más de la Ciudad de México: Estudio de base poblacional [Prevalence and risks associated with adult patients with asthma aged 40 years or more from Mexico City: A population-based study]. Salud Publica Mex. 2012;54:425-32. Spanish. https://doi. org/10.1590/s0036-36342012000400013

13. Bedolla-Barajas M, Valdez-López F, Alcalá-Padilla G, BedollaPulido TI, Rivera-Mejia V, Morales-Romero J. Prevalence and factors associated to peanut allergy in Mexican school children. Allergol Immunopathol. 2017;45:69-76. https://doi.org/10. 1016/j.aller.2016.04.013

14. Bedolla-Barajas $M$, Macriz-Romero $N$, Jara-Ettinger $A C$, Macriz-Romero M, Fregoso-Fregoso M, Morales-Romero J.
Autorreporte de alergia al látex en estudiantes de medicina: Prevalencia y factores asociados [Self-report of latex allergy in medical students: Prevalence and associated factors]. Rev Alerg Mex. 2018;65:10-18. Spanish. https://doi.org/10.29262/ ram.v65i1.290

15. Halpin DMG, Faner R, Sibila O, Badia JR, Agusti A. Do chronic respiratory diseases or their treatment affect the risk of SARSCoV-2 infection? Lancet Respir Med. 2020;8:436-8. https://doi. org/10.1016/S2213-2600(20)30167-3

16. Zhu Z, Hasegawa K, Ma B, Fujiogi M, Camargo CA Jr, Liang L. Association of asthma and its genetic predisposition with the risk of severe COVID-19. J Allergy Clin Immunol. 2020;46(2):327-9.e4.. https://doi.org/10.1016/j.jaci. 2020.06.001

17. Jackson DJ, Busse WW, Bacharier LB, Kattan M, O'Connor GT, Wood RA, et al. Association of respiratory allergy, asthma, and expression of the SARS-CoV-2 receptor ACE2. J Allergy Clin Immunol. 2020;146:203-206.e3. https://doi.org/10.1016/j. jaci.2020.04.009

18. Abiad HF, Alameddine VM, Hallit S, Torbey P-H, Mroueh S, Yazbek N, et al. Aeroallergen sensitization in Lebanese asthmatic children: the results of a cohort national study. Environ Sci Pollut Res Int. 2020;27:5597-605. https://doi.org/10.1007/ s11356-019-07234-z

19. Kwizera R, Wadda V, Mugenyi L, Aanyu-Tukamuhebwa $\mathrm{H}$, Nyale G, Yimer G, et al. Skin prick reactivity among asthmatics in East Africa. World Allergy Organ J. 2020;13:100130. https://doi.org/10.1016/j.waojou.2020.100130

20. Zhang J-J, Dong X, Cao Y-Y, Yuan Y-D, Yang Y-B, Yan Y-Q, et al. Clinical characteristics of 140 patients infected with SARSCoV-2 in Wuhan, China. Allergy. 2020;75:1730-41. https://doi. org/10.1111/all.14238

21. Green I, Merzon E, Vinker S, Golan-Cohen A, Magen E. COVID-19 susceptibility in bronchial asthma. J Allergy Clin Immunol Pract. 2021; 9(2):684-92. . https://doi.org/10.1016/j. jaip.2020.11.020.

22. Grandbastien M, Piotin A, Godet J, Abessolo-Amougou I, Ederlé $C$, Enache I, et al. SARS-CoV-2 Pneumonia in Hospitalized Asthmatic Patients Did Not Induce Severe Exacerbation. J Allergy Clin Immunol Pract. 2020;8:2600-7. https://doi.org/10.1016/j.jaip.2020.06.032.

23. Chhiba KD, Patel GB, Vu THT, Chen MM, Guo A, Kudlaty E, et al. Prevalence and characterization of asthma in hospitalized and nonhospitalized patients with COVID-19. J Allergy Clin Immunol. 2020;146:307-314.e4. https://doi.org/10.1016/j. jaci.2020.06.010.

24. Lieberman-Cribbin W, Rapp J, Alpert N, Tuminello S, Taioli E. The impact of asthma on mortality in patients with COVID19. Chest. 2020; 158(6): 2290-1. https://doi.org/10.1016/j. chest.2020.05.575. 